\title{
DETERMINANTS OF UNSUCCESFUL EXCLUSIVE BREASTFEEDING - A SCOPING REVIEW
}

\author{
Yuliandary Yunus ${ }^{1 \mathrm{i}}$, \\ Prima Dhewi Ratrikaningtyas², \\ Dwi Ernawati ${ }^{3}$ \\ ${ }^{1}$ Master Program in Midwifery, \\ Faculty of Health Science, \\ Universitas Aisyiyah Yogyakarta, \\ Yogyakarta, Indonesia \\ 2Master Program in Public Health, \\ Faculty of Medical, Public Health, and Nursing, \\ Universitas Gadjah Mada, \\ Yogyakarta, Indonesia \\ ${ }^{3}$ Master Program in Midwifery, \\ Faculty of Health Science, \\ Universitas Aisyiyah Yogyakarta, \\ Yogyakarta, Indonesia
}

\begin{abstract}
:
Background: Globally, 40\% of children under the age of 6 months are exclusively breastfed. The results of the Basic Health Research (RISKESDAS) in 2018, the rate of exclusive breastfeeding for infants aged 0-6 months, it merely reached $37.3 \%$. Purpose: To discover the factors that affected the failure of exclusive breastfeeding. Method: Scoping review adapted the Arskey and O'Malley framework, using a database from PubMed, Willey. and ScienceDirect. Finding: 21 articles out of 1563 selected based on inclusion and exclusion criteria. Factors related to the failure of exclusive breastfeeding were divided into three factors, namely (1) sociodemographic factors consist of knowledge, occupation, age, environment and socio-culture, (2) health factors consist maternal parity, BMI, and psychological, (3) psychosocial factors consist of attitudes, breastfeeding intentions, family support, support from health workers and information obtained by the mother. Conclusion: The factors that most affected the failure of exclusive breastfeeding were the lack of family support for breastfeeding mothers, the support of passive health workers in providing information about exclusive breastfeeding and the work status of mothers who required mothers to work outside the home. In-depth research must be needed to find out the best strategy in increasing the achievement of exclusive breastfeeding.
\end{abstract}

i Correspondence: email liayunus15@icloud.com 
Keywords: exclusive breastfeeding failure, inhibiting factors for breastfeeding, scoping review

\section{Introduction}

Globally, $40 \%$ of children under 6 months of age are exclusively breastfed. In America $57.6 \%$ of mothers breastfeed until the age of 6 months but only $25 \%$ who breastfeed exclusively [1]. The Indonesian Basic Health Survey (IDHS) which was undertaken for 4 periods, it revealed exclusive breastfeeding from 2002 to 2017 had increased. The results of the IDHS survey explained that in 2002 the coverage of exclusive breastfeeding reached $40 \%$, then decreased in 2007 to $32 \%$, however the survey results prove that in three periods from 2007 to 2017 there was a significant increase of $42 \%$ in 2012 and $52 \%$ in 2017. This showed the highest increase in the success of exclusive breastfeeding occurred in 2017.

One of the six main global nutrition goals in the World Health Organization (WHO) Comprehensive Nutrition, Maternal and Infant Plan is to increase the practice of exclusive breastfeeding during the first 6 months to at least 50\% [2]. WHO and the United Nations Children's Fund (UNICEF) launched the Baby-friendly Hospital Initiative (BFHI) to improve breastfeeding practices and support breastfeeding in maternity wards around the world. Efforts to support the increase in exclusive breastfeeding can be seen from the issuance of various international and national recognitions or agreements aimed at protecting, promoting and supporting breastfeeding. Thus, it is expected that every mother around the world can carry out breastfeeding and every baby around the world has the right to get breast milk [3]. In accordance with the $3^{\text {rd }}$ of Sustainable Development Goals (SDGs), the $2^{\text {nd }}$ target, namely by 2030, it ends preventable infant and child mortality, with all countries attempt to reduce the Neonatal Mortality Rate to at least 12 per 1,000 live births (SDGS, 2017). Regarding to the problems above, the purpose of this scoping review was to find out the factors that affected the failure of exclusive breastfeeding from the results of previous studies.

\section{Method}

\subsection{Design}

This review used the clustering method suggested by Arksey and O'Malley. The stages carried out in a scoping review review, it consists of: (1) identifying scoping review questions, (2) in a scoping review review consisting of: (1) identifying scoping review questions, (2) identifying relevant articles, (3) article selection, (4) charting data, (5) compiling, summarizing and reporting results [4]. 


\subsection{Identify Relevant Studies}

Table 1: Research Question Framework

\begin{tabular}{|c|l|l|l|}
\hline \multicolumn{1}{|c|}{$\begin{array}{c}\text { P } \\
\text { (Population) }\end{array}$} & \multicolumn{1}{c|}{$\begin{array}{c}\text { E } \\
\text { (Exposure) }\end{array}$} & \multicolumn{1}{c|}{$\begin{array}{c}\text { O } \\
\text { (Outcome) }\end{array}$} & $\begin{array}{c}\text { S } \\
\text { (Study Design) }\end{array}$ \\
\hline $\begin{array}{l}\text { The mothers who have } \\
\text { babies age 6-12 months }\end{array}$ & $\begin{array}{l}\text { The factors which } \\
\text { influence exclusive } \\
\text { breastmilk failure }\end{array}$ & $\begin{array}{l}\text { Baby with failure of } \\
\text { exclusive breastmilk }\end{array}$ & $\begin{array}{l}\text { All relevant research } \\
\text { design with the scoping } \\
\text { review purposes }\end{array}$ \\
\hline
\end{tabular}

Based on the framework above, the Scoping review question proposed is "what do factors affect the failure of exclusive breastfeeding?".

a. Inclusion criteria

- Articles with the population in this study were mothers who have babies aged 6 months-12 months.

- Articles published from January 2010- December 2020.

- Published in English.

- Articles were complete and accessible.

- Articles that discussed the factors that affected the failure of exclusive breastfeeding.

- Peer-reviewed articles, including primary research.

- Literature review.

b. Exclusion criteria

- Opinion papers.

- Grey literature in the form of conference papers, conference proceedings, reports, theses or dissertations.

c. Articles were searched using Boolean, namely AND, OR, NOT and Truncation $\left(^{*}\right)$ as a link to combine or exclude keywords in the search so that more focused and relevant results are obtained. The keywords used in the search process are (exclusive* OR select* OR share* OR only OR sole OR privilege ${ }^{*}$ ) AND (breastfeed* OR bottlefeed* OR suck* OR lactate OR givesuck OR feed*) AND (factor* OR causes OR influence* OR determinant* OR component OR element* OR part OR section* OR causal factor OR cognitive factor*) AND (failure* OR fate OR destiny OR fortune OR happen* OR adversity OR bad luck OR disaster).

\subsection{Article Selection}

The data filtering process used PRISM flowchart. 


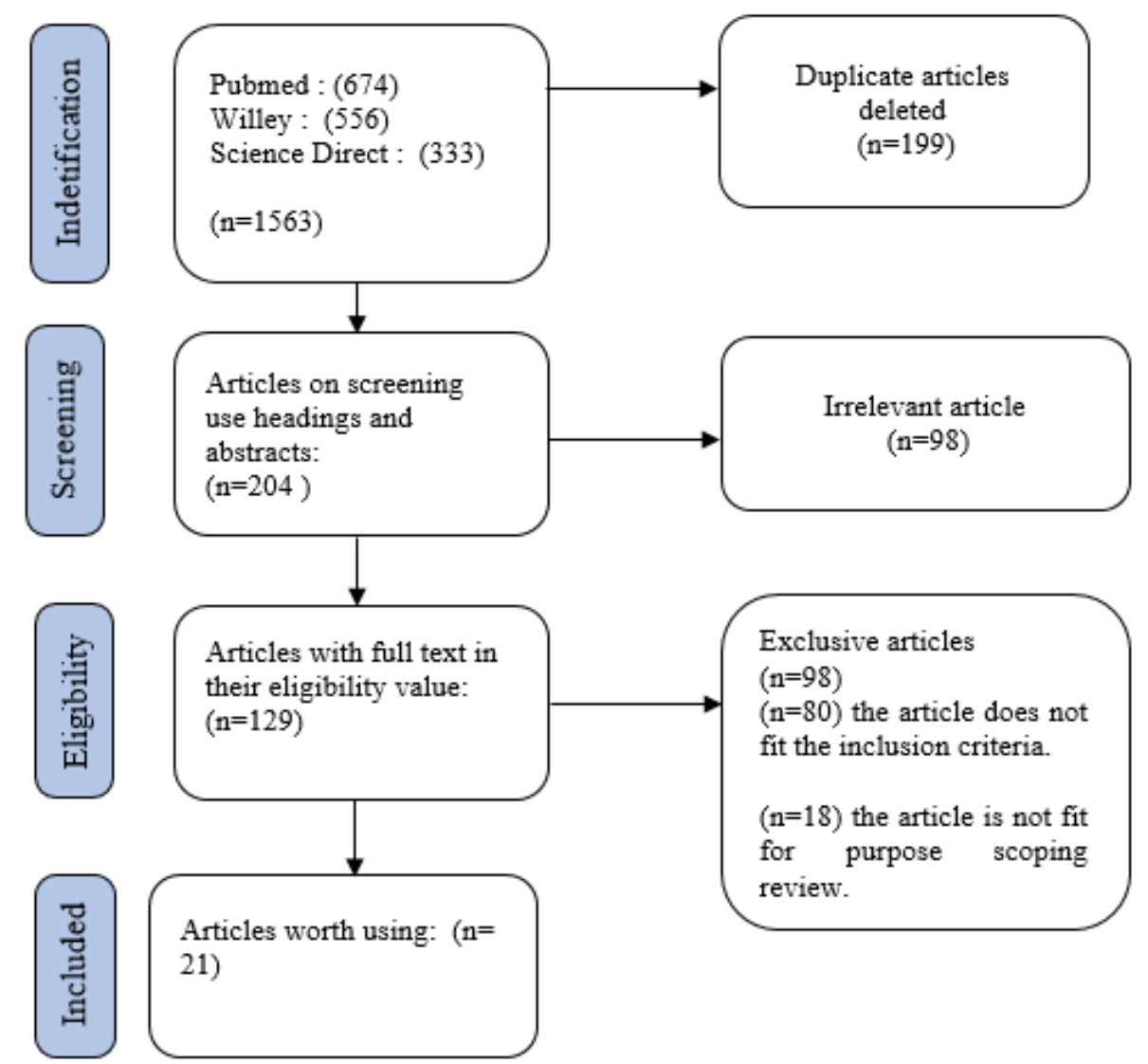

Figure 1: PRISM Flowchart

\subsection{Data Charting}

Data from 21 articles were included in a table with main criteria such as research location, study population, research objectives, methodology and important findings or recommendations. The researcher recorded the information independently and compared the data reviewed.

Table 2: Data Charting

\begin{tabular}{|c|c|c|}
\hline Title/Author/Year/Grade & Aim & Result \\
\hline $\begin{array}{l}\text { 'I just don't think it's that natural': } \\
\text { adolescent mothers' constructions of } \\
\text { breastfeeding as deviant/[5]/ Q2 }\end{array}$ & $\begin{array}{l}\text { Assessing deviant behavior } \\
\text { during breastfeeding in young } \\
\text { mothers }\end{array}$ & $\begin{array}{l}\text { There are two factors, the cultural } \\
\text { habit of giving PASI before the } \\
\text { baby is } 6 \text { months old, the attitude of } \\
\text { the mother who is doubtful about } \\
\text { the benefits of breastfeeding. }\end{array}$ \\
\hline $\begin{array}{l}\text { Actual exclusive breastfeeding rates and } \\
\text { determinants among a cohort of } \\
\text { children living in } \\
\text { Gampaha district Sri Lanka: A } \\
\text { prospective } \\
\text { observational study/ [6]/Q1 }\end{array}$ & $\begin{array}{l}\text { Determining the actual number } \\
\text { of exclusive breastfeeding in the } \\
\text { Sri Lankan children group and } \\
\text { to determine the reasons that } \\
\text { lead to early cessation of } \\
\text { breastfeeding before the age of } \\
\text { six months. }\end{array}$ & $\begin{array}{l}\text { The rates of exclusive breastfeeding } \\
\text { at two, four and six months were } \\
98.0 \%, 75.4 \% \text { and } 71.3 \% \text {, } \\
\text { respectively. The main reason for } \\
\text { stopping exclusive breastfeeding } \\
\text { between two and four months is } \\
\text { worry. }\end{array}$ \\
\hline $\begin{array}{l}\text { Breastfeeding Difficulties and Risk for } \\
\text { Early Breastfeeding Cessation/ (Gianni } \\
\text { et al., 2019)/Q2 }\end{array}$ & $\begin{array}{l}\text { Investigating the breastfeeding } \\
\text { culture that the mother has } \\
\text { experienced since the baby was } \\
\text { born in the first month and its } \\
\text { relationship with early cessation } \\
\text { of breastfeeding. }\end{array}$ & $\begin{array}{l}\text { The result of this research is culture } \\
\text { in the society, and passive health } \\
\text { workers }\end{array}$ \\
\hline
\end{tabular}




\begin{tabular}{|c|c|c|}
\hline $\begin{array}{l}\text { Barriers to breast-feeding in obese } \\
\text { women: A qualitative } \\
\text { exploration/(Keely et aI., 2015)/Q1 }\end{array}$ & $\begin{array}{l}\text { To identify barriers to } \\
\text { breastfeeding success and } \\
\text { reasons for introducing infant } \\
\text { formula and/or stopping } \\
\text { breastfeeding. }\end{array}$ & $\begin{array}{l}\text { Low support during postpartum } \\
\text { breastfeeding. And the rise of } \\
\text { formula milk advertisements }\end{array}$ \\
\hline $\begin{array}{l}\text { Normative vs. attitudinal considerations } \\
\text { in breastfeeding } \\
\text { behavior: multifaceted social influences } \\
\text { in a developing country } \\
\text { context/[9]/Q2 }\end{array}$ & $\begin{array}{l}\text { The purpose of this research is } \\
\text { to find out the behavior that } \\
\text { causes the failure of exclusive } \\
\text { breastfeeding in the social } \\
\text { environment in Turkish women } \\
\text { who have just given birth. }\end{array}$ & $\begin{array}{l}\text { Behavior related to feeding babies } \\
\text { starts from a series of intentions, } \\
\text { attitudes, and social factors as well } \\
\text { as information obtained by mothers } \\
\text { before and after giving birth. }\end{array}$ \\
\hline $\begin{array}{l}\text { Incorrect advice: the most significant } \\
\text { negative determinant on breast feeding } \\
\text { in Malta/ (Attard Montalto et al., } \\
\text { 2010)/Q2 }\end{array}$ & $\begin{array}{l}\text { This study aims to review } \\
\text { breastfeeding rates in Malta in } \\
\text { the first six months of life and } \\
\text { identify reasons why mothers } \\
\text { discontinue breastfeeding in this } \\
\text { small country. }\end{array}$ & $\begin{array}{l}\text { the rate of reduction in } \\
\text { breastfeeding was high with only } \\
152(38 \%) \text { of the } 403 \text { infants } \\
\text { analyzed still breastfeeding at six } \\
\text { months. Reasons for stopping } \\
\text { breastfeeding are categorized by: } \\
\text { mother's choice; medical reasons; } \\
\text { less information; social reasons, } \\
\text { wrong advice and no reasons } \\
\text { given. }\end{array}$ \\
\hline $\begin{array}{l}\text { Factors associated with initiation and } \\
\text { exclusive breastfeeding at hospital } \\
\text { discharge: Late preterm compared to } 37 \\
\text { week gestation mother and infant } \\
\text { cohort/(Ayton } \text { et al., 2012)/Q1 }\end{array}$ & $\begin{array}{l}\text { The purpose of this research is } \\
\text { to identify factors that affect } \\
\text { mothers and infants on the } \\
\text { failure to exclusively breastfeed } \\
\text { after being discharged from the } \\
\text { hospital. }\end{array}$ & $\begin{array}{l}\text { In this study, the factors that affect } \\
\text { breastfeeding failure are gestational } \\
\text { age, caesarean section, and } \\
\text { premature birth. }\end{array}$ \\
\hline $\begin{array}{l}\text { Women's experiences of ceasing to } \\
\text { breastfeed: Australian qualitative study/ } \\
{[12] / Q 2}\end{array}$ & $\begin{array}{l}\text { The aim of this research is to } \\
\text { find out the reason of mothers } \\
\text { who stop breastfeeding } \\
\text { exclusively }\end{array}$ & $\begin{array}{l}\text { Mothers considers that } \\
\text { breastfeeding as something } \\
\text { 'natural' and 'best' and formula } \\
\text { milk as something 'unlawful' and } \\
\text { 'unnatural'. resources such as } \\
\text { support from husband, family, and } \\
\text { problems when preparing } \\
\text { expressed breast milk. }\end{array}$ \\
\hline $\begin{array}{l}\text { Initiation and continuation of } \\
\text { breastfeeding among Jordanian first- } \\
\text { time mothers: a prospective cohort } \\
\text { study/(AI Dasoqi et aI., 2018)/Q1 }\end{array}$ & $\begin{array}{l}\text { The purpose of this study is to } \\
\text { determine the rate of early } \\
\text { initiation of breastfeeding and } \\
\text { the continuity of exclusive } \\
\text { breastfeeding, and their } \\
\text { relationship to } \\
\text { sociodemographic factors. }\end{array}$ & $\begin{array}{l}\text { This study extends the } \\
\text { comprehension based on the } \\
\text { evidence that intrapartum } \\
\text { medications and procedures, as } \\
\text { well as sociodemographic } \\
\text { characteristics, can influence } \\
\text { breastfeeding initiation and } \\
\text { breastfeeding continuation. }\end{array}$ \\
\hline $\begin{array}{l}\text { Typologies of postnatal support and } \\
\text { breastfeeding at two months in the } \\
\text { UK/[14]/Q2 }\end{array}$ & $\begin{array}{l}\text { The aim of this study is to } \\
\text { explore typologies of postnatal } \\
\text { support and their relationship } \\
\text { to breastfeeding failure. }\end{array}$ & $\begin{array}{l}\text { The identification results from this } \\
\text { study were three different types of } \\
\text { postnatal support. These findings } \\
\text { highlight the complexity of family } \\
\text { support and its potential impact on } \\
\text { exclusive breastfeeding, the lack of } \\
\text { support from health workers also } \\
\text { affects the achievement of } \\
\text { successful breastfeeding. }\end{array}$ \\
\hline $\begin{array}{l}\text { Factors associated with duration of } \\
\text { breastfeeding in Spain: a cohort study/ } \\
\text { (Iechosa-Muñiz et al., 2020)/Q1 }\end{array}$ & $\begin{array}{l}\text { The purpose of this study is to } \\
\text { find out the factors that affect } \\
\text { the failure of breastfeeding. }\end{array}$ & $\begin{array}{l}\text { The result found that the } \\
\text { association between gestational age } \\
\text { and duration of breastfeeding } \\
\text { disappeared in the multivariate } \\
\text { setting when adjusting for birth }\end{array}$ \\
\hline
\end{tabular}




\begin{tabular}{|c|c|c|}
\hline & & $\begin{array}{l}\text { weight, suggesting that lower birth } \\
\text { weight was the dominant factor in } \\
\text { this finding. }\end{array}$ \\
\hline $\begin{array}{l}\text { Predictors of breastfeeding initiation in } \\
\text { Hong Kong and Mainland China born } \\
\text { mothers/(Iok, Bai and Tarrant, 2015)/Q2 }\end{array}$ & $\begin{array}{l}\text { This study aims to find out the } \\
\text { factors associated with } \\
\text { breastfeeding initiation in } \\
\text { mothers born in Hong Kong } \\
\text { and mothers born in Mainland } \\
\text { China but who live and give } \\
\text { birth in Hong Kong. }\end{array}$ & $\begin{array}{l}\text { The results in this study explain } \\
\text { that the factors that affect mothers } \\
\text { in starting breastfeeding are parity, }\end{array}$ \\
\hline $\begin{array}{l}\text { Rates and determinants of early } \\
\text { initiation of } \\
\text { breastfeeding and exclusive breast } \\
\text { feeding at } \\
42 \text { days postnatal in six low and middle- } \\
\text { income } \\
\text { countries: A prospective cohort } \\
\text { study/(PateI et aI., 2015)/Q2 }\end{array}$ & $\begin{array}{l}\text { The aim of this research is } \\
\text { factors associated with failure to } \\
\text { initiate early breastfeeding and } \\
\text { exclusive breastfeeding at } 42 \\
\text { days postpartum. }\end{array}$ & $\begin{array}{l}\text { In this large population-based } \\
\text { prospective observational study, it } \\
\text { was found that breastfeeding } \\
\text { failure was influenced by failure to } \\
\text { initiate early breastfeeding at birth. }\end{array}$ \\
\hline $\begin{array}{l}\text { Mothers' Expectations and Factors } \\
\text { Influencing Exclusive Breastfeeding } \\
\text { during the First } 6 \text { Months/ (Santacruz- } \\
\text { Salas et aI., 2020)/Q1 }\end{array}$ & $\begin{array}{l}\text { The purpose of this study is to } \\
\text { find out the expectations of } \\
\text { Spanish women regarding } \\
\text { exclusive breastfeeding (EB) and } \\
\text { the effect of expectations and } \\
\text { other factors on exclusive } \\
\text { breastfeeding during the first } 6 \\
\text { months. }\end{array}$ & $\begin{array}{l}\text { Women's expectations about the } \\
\text { desired duration of exclusive } \\
\text { breastfeeding were not achieved } \\
\text { due to personal factors, maternal } \\
\text { age and women's family } \\
\text { environment. }\end{array}$ \\
\hline $\begin{array}{l}\text { Sensitivity of the Breastfeeding } \\
\text { Motivational Measurement Scale: A } \\
\text { Known Group Analysis of First Time } \\
\text { Mothers/(StockdaIe } \text { et aI., 2013)/Q1 }\end{array}$ & $\begin{array}{l}\text { The purpose of this study is to } \\
\text { find out why first-time mothers } \\
\text { are more likely to stop } \\
\text { breastfeeding than mothers who } \\
\text { are experienced in exclusive } \\
\text { breastfeeding. }\end{array}$ & $\begin{array}{l}\text { The results of the analysis in this } \\
\text { study indicate that mothers who } \\
\text { are breastfeeding for the first time } \\
\text { have doubts about themselves } \\
\text { compared to mothers who have } \\
\text { experienced }\end{array}$ \\
\hline $\begin{array}{l}\text { Factors Contributing to Early } \\
\text { Breastfeeding Cessation Among } \\
\text { Chinese Mothers; an exploratory } \\
\text { study/(Tarrant, Dodgson, WU,2019) Q2 }\end{array}$ & $\begin{array}{l}\text { to identify contributing factors } \\
\text { that can be improved to help } \\
\text { women breastfeed longer. }\end{array}$ & $\begin{array}{l}\text { The factors found in this research } \\
\text { were, inappropriate expectations, } \\
\text { breastfeeding experience. }\end{array}$ \\
\hline $\begin{array}{l}\text { Shame if you do - shame if you don't: } \\
\text { women's experiences of infant feeding/ } \\
{[20] / Q 1}\end{array}$ & $\begin{array}{l}\text { The purpose of this study is to } \\
\text { provide a perspective on how } \\
\text { mothers feel when they fail to } \\
\text { exclusively breastfeed. }\end{array}$ & $\begin{array}{l}\text { The result indicated that } \\
\text { breastfeeding and non- } \\
\text { breastfeeding mothers felt } \\
\text { embarrassed. Breastfeeding } \\
\text { mothers may be at risk of feeling } \\
\text { embarrassed if they breastfeed, } \\
\text { especially in public, as some people } \\
\text { felt embarrassed when part of their } \\
\text { body was exposed. }\end{array}$ \\
\hline $\begin{array}{l}\text { Breastfeeding Self-efficacy: A Critical } \\
\text { Review of Available } \\
\text { Instruments/(Tuthill et aI., 2016)/Q1 }\end{array}$ & $\begin{array}{l}\text { The aim of the study is to } \\
\text { identify, compare, and critically } \\
\text { review the available } \\
\text { breastfeeding seIf-efficacy } \\
\text { instruments }\end{array}$ & $\begin{array}{l}\text { Knowledge of breastfeeding self- } \\
\text { efficacy through sharing resources } \\
\text { and advancing previous work can } \\
\text { result in fewer instruments, }\end{array}$ \\
\hline $\begin{array}{l}\text { 'I thought it would keep them all quiet'. } \\
\text { Women's experiences of breastfeeding } \\
\text { as illusions of compliance: an } \\
\text { interpretive phenomenological } \\
\text { study/[22]/Q2 }\end{array}$ & $\begin{array}{l}\text { The purpose of this research is } \\
\text { to find out the experiences of } \\
\text { mothers who have failed in } \\
\text { exclusive breastfeeding. }\end{array}$ & $\begin{array}{l}\text { The findings reveal that women's } \\
\text { breastfeeding behavior is socially } \\
\text { mediated. They adopt the image of } \\
\text { a good mother by following the } \\
\text { moral obligation to breastfeed } \\
\text { immediately after their baby is } \\
\text { born. }\end{array}$ \\
\hline
\end{tabular}




\begin{tabular}{|l|l|l|}
\hline \hline $\begin{array}{l}\text { 'It should be the most natural thing in } \\
\text { the world: exploring first-time mothers' } \\
\text { breastfeeding difficulties in the UK } \\
\text { using audio-diaries and } \\
\text { interviews/(Williamson } \text { et aI., 2012)/Q2 }\end{array}$ & $\begin{array}{l}\text { This study aims to broaden our } \\
\text { understanding of the potential } \\
\text { impact on women who } \\
\text { encounter breastfeeding } \\
\text { challenges by focusing on } \\
\text { groups experiencing } \\
\text { considerable difficulty in the } \\
\text { early postpartum period. }\end{array}$ & $\begin{array}{l}\text { Factors that worsen their situation } \\
\text { are being around them, starting } \\
\text { from family support, surrounding } \\
\text { communities, and health workers. } \\
\text { The thing that must be considered } \\
\text { is changing the perspective of } \\
\text { people around about the } \\
\text { importance of exclusive } \\
\text { breastfeeding so that mothers get } \\
\text { full support in exclusive } \\
\text { breastfeeding. }\end{array}$ \\
\hline $\begin{array}{l}\text { Relactation in lactation failure and Low } \\
\text { milk supply/(SaIih, 2018)/Q2 }\end{array}$ & $\begin{array}{l}\text { The aim of the research is to } \\
\text { find out the causes of failure in } \\
\text { lactation, factors that affect } \\
\text { relactation in mothers who have } \\
\text { little breast milk, }\end{array}$ & $\begin{array}{l}\text { Researchers found that age is one of } \\
\text { the factors that affects lactation and } \\
\text { relactation, in addition to faster } \\
\text { complementary feeding, lack of } \\
\text { support from family and lack of } \\
\text { support from health workers. }\end{array}$ \\
\hline
\end{tabular}

\subsection{Presentation of data/results and conclusions}

The themes that have been included in the purpose of this article include sociodemographic factors, health factors, and psychosocial factors. The sub-themes for sociodemographic themes are: education, occupation, age, and socio-culture. The sub-themes for health factors are: parity, BMI, and psychological. The sub-themes for psycho-social factors are: attitudes, breastfeeding intentions, husband and family support, support from health workers, and information.

Table 3: Mapping Themes

\begin{tabular}{|l|l|l|l|}
\hline No & Themes & Sub-themes & Articles \\
\hline 1 & Sociodemography & A. Knowledge & a. A1, A9, A12 \\
& & B. Occupation & b. A2, A11, A12, A15 \\
& & C. Age & c. A14, A20 \\
& & D. Social Culture & d. A1, A3, A20 \\
\hline 2 & Health & A. Parity & a. A2, A7 \\
& & B. IMD & b. A8, A12 \\
& & C. Psychology & c. A11, A12, A13 \\
\hline 3 & Psychosocial & A. Attitude & a. A1, A3, A4 \\
& & B. Breastfeeding intention & b. A4, A5, A15, \\
& & C. Family Support & c. A3, A4, A16, A20 \\
& & D. Health Energy Support & d. A5, A18, A20, A21 \\
& & E. Information & e. A6 \\
\hline
\end{tabular}

\section{Finding and Discussion}

\subsection{Sociodemographic Factors}

\section{a. Knowledge}

The results of the study stated that there was a relationship between knowledge and failure in exclusive breastfeeding [25]. Knowledge of mothers who are in the poor category is caused by mothers who think that there is little milk coming out of the 
mother's breasts so that mothers feel worried if the baby will not get enough milk from the mother, so mothers think that the food needs for their babies can only be met by giving formula milk. In addition, there are still mothers who think that breast milk cannot provide nutrition according to the nutritional needs of babies [26].

In some areas with a 'formula/bottle milk culture', girls and young women in these areas have negative thoughts about breastfeeding, according to their daily experiences. It is not surprising that adult women in this area have little or no information, experience in breastfeeding and confidence in their ability to breastfeed [27].

In the condition of someone who does not have knowledge about exclusive breastfeeding, and she only has knowledge of local culture in the form of food ideology for babies. This knowledge of local culture is said to be knowledge about non-exclusive breastfeeding, and is clearly a factor that hinders the practice of exclusive breastfeeding [3].

\section{b. Job}

Globally, there is an economic role in the practice of exclusive breastfeeding. Working mothers are at risk of not giving exclusive breastfeeding to their babies, especially mothers who work outside the home who demand that mothers leave their babies. Mothers who have jobs in the informal sector can provide more exclusive breastfeeding, compared to mothers who have jobs in the formal sector. This is because informal work has more flexible working hours than formal (bound) work [28].

Jamie et aI., 2020 reveals that the number of mothers who breastfeed in low- or middle-income countries is higher than in high-income countries [5]. Alive argues that less than $40 \%$ of infants under 6 months of age in low- and middle-income developing countries are exclusively breastfed, and one-third of infants aged 6-24 months are not breastfed. Meanwhile, the number of children who are breastfed until the age of 13 months in developed countries with high incomes is less than 20 percent. In fact, mothers with higher education and economics, it is known that the duration of breastfeeding is longer [2].

\section{c. Age}

Based on research conducted by the American of Pediatrics, it is known that the rate of exclusive breastfeeding is highest in women aged 35 years and the lowest in women under the age of 20 years. [12]. Older mothers are less likely to breastfeed than younger mothers, and the lowest percentage of breastfeeding occurs in adolescent mothers [14].

According to Keely (2015), mother's age at childbirth can influence the onset of lactation. Mothers over 30 years of age may experience a slightly slower onset of lactation when compared to a younger age [8]. The age that can accelerate the onset of lactation in mothers after giving birth is between 20-30 years. At that age, the reproductive organs have grown perfectly and matured [29]. 


\section{d. Socio-Cultural}

Socio-culture has a big impact on the success of breastfeeding for 6 months. Research conducted in Africa revealed that exclusive breastfeeding was very small in some areas, namely no more than 59\%. This is due to the delay in starting (IMD) and the practice of non-exclusive breastfeeding. This delay in IMD is due to cultural practices such as the belief that colostrum is dirty milk so it is harmful to the baby, the belief that mothers are required to rest and purify themselves after childbirth and perform some rituals and pray before breastfeeding. [10]. The baby after birth is given water or a potion by the motherin-law or other family members because they believe that it relieves a thirsty baby and is trusted to welcome the baby born [7].

\subsection{Health Factor}

\section{a. Parity}

Parity in this review is the frequency of mother giving birth, whether she gives birth live or not. Primiparous mothers do not give exclusive breastfeeding due to lack of milk on the first and second day after giving birth. In addition, there are mothers whose children do not want to breastfeed; therefore the mother chooses to give formula milk as a companion to breast milk. Most of the multiparous mothers did not give exclusive breastfeeding for 6 months because of their previous non-exclusive breastfeeding experience [20].

Based on Kelly (2015), the experience of breastfeeding affects the mother to stop breastfeeding. Mothers who do not have experience in exclusive breastfeeding can experience difficulties in overcoming obstacles during breastfeeding [8]. According to Silva (2019), there is a significant difference in primiparous and multiparous women, seen in prenatal intentions and intentions, as well as experience while in hospital [31]. Some mothers give reasons for primiparas not breastfeeding because of the delay in breastfeeding during the full six months and chose to give formula milk, an inappropriate way of giving breast milk so that the baby has difficulty tightening the nipples and sucking; the breast doesn't flow so it thinks the milk that comes out is not enough to fill the baby [32].

\section{b. IMD}

IMD is one of the guidelines for successful breastfeeding introduced by WHO/UNICEF in 2005 regarding the promotion and support of breastfeeding, namely: "Start breastfeeding immediately after birth (within one hour)" [33]. National data in the United States illustrates that although mothers who have had IMD since birth have increased, many of them cannot meet the requirements for exclusive breastfeeding as recommended in terms of exclusivity and duration of breastfeeding. The highest percentage of this failure is found in the first week after the baby is born [5]. Statements of insufficient breast milk are the most common reason for mothers to stop breastfeeding and it occurs in most of the population in the world. [20]. 


\section{c. Psychology}

Research result Tuthill (2016) mentions that there is an influence between maternal psychology and exclusive breastfeeding. Mothers who do not have psychological disorders are more likely to give exclusive breastfeeding for 6 months. However, there are still mothers with good psychological conditions and choose not to breastfeed their babies. This is influenced by the health status of the mother and baby [21].

Disorders that exist in the mother's psychology can interfere with the breastfeeding process, including the mother feeling restless when breast milk does not flow and feeling uncomfortable during breastfeeding. If the milk does not come out much on the first and second day after giving birth, the mother immediately gives formula to the baby because she is worried that if the baby only relies on breast milk, the baby will be fussy because of hunger. [7]. One of the causes of the failure of exclusive breastfeeding is by mothers who are not physically and mentally ready to breastfeed. Therefore, many mothers decide to give preacteal foods in the form of formula if breast milk does not flow at the beginning of breastfeeding [20].

\subsection{Psychosocial}

\section{a. Attitude}

Several articles reveal that there is a relationship between attitude and failure to breastfeed. Supportive mothers will try their best to express their support by practicing exclusive breastfeeding. In contrast to mothers who already have an unsupportive attitude, usually they will be apathetic and refuse to give exclusive breastfeeding for various reasons [12]. In general, reasons for non-exclusive breastfeeding include unfounded fears about insufficient or poor quality breast milk, delay in initiating breastfeeding, colostrum release, incorrect breastfeeding technique and the mistaken belief that the baby is thirsty, and needs other fluids [7]. Knowledge of exclusive breastfeeding and the lack of motivation in exclusive breastfeeding, affect the attitude of mothers because local cultural knowledge is still attached to infant feeding, such as giving honey and the mother's lack of confidence that breastfeeding is not enough for her child [34].

\section{b. Breastfeeding Intention}

Mother's intention in the study was defined as the desire or will of the mother to breastfeed exclusively. Mother's intention to exclusively breastfeed is a step before exclusive breastfeeding behavior occurs [35]. In the theory of reasoned action, it is said that intentions can be influenced by a person's subjective attitudes and norms [36].

Research of Tewabe (2017) argued that the low coverage of exclusive breastfeeding was due to the low intention of pregnant women to provide exclusive breastfeeding [37]. It can be seen in the results of the review above which explains that pregnant women decide to return to work after the maternity leave period is over, from this explanation mothers who have breastfeeding intentions do not have the readiness to exclusively breastfeed their babies, this causes indicators of mothers' intentions to breastfeed their babies. not fulfilled [38]. 


\section{c. Support of Family}

In the research conducted Mattar (2019), it can be seen that mothers who do not give exclusive breastfeeding, they are more likely to receive less information support from their families, especially the benefits and advantages of breastfeeding, so that the lack of information has an impact on the mother's low knowledge about exclusive breastfeeding, families, especially men, are an important part of the success or failure of breastfeeding. [39], because the information conveyed by the family (husband) can support the mother for smooth milk production (let down reflex) which greatly affects the condition of the mother's feelings [40].

Assessment support that is not obtained by mothers who do not exclusively breastfeed their babies causes mothers to feel less valued so that mothers do not have the will or interest to exclusively breastfeed their babies. [40]. In the research conducted by Ie (2018) it can be seen that the lack of support for the mother is that the family does not help the mother to provide nutritious food, nor does it help the mother for the baby during breastfeeding, the mother's homework is not assisted by the family, the mother has to do the housework herself, while the mother also has to breastfeed the baby [41].

\section{d. Healthcare Support}

Research result of (2019) describes the support of health workers in the failure of exclusive breastfeeding shows that the proportion of health workers who do not support the respondents are more likely to experience the failure of exclusive breastfeeding, which is $46.3 \%$ compared to respondents who receive support, which is $30.9 \%$ [7]. The role of health workers, especially midwives, can be in the form of guidance and consultation on breastfeeding problems in infants. Convincing mothers to be able to breastfeed their own babies and the support of health workers can provide information about the benefits of exclusive breastfeeding and can influence the behavior of mothers to give exclusive breastfeeding [42].

The passive role of health workers in the practice of exclusive breastfeeding is more dominant than the active role. The research data shows that most of the respondents who received formula milk for the first time were advised by the midwife and when they returned home they received formula milk [43].

\section{e. Information}

Research of Lok, Bai and Tarrant, 2015 explained that some respondents received information through the media. Mother said she was interested in the promotion of formula milk shown. They reveal that formula milk is good and attractive, and it encourages mothers to believe that formula milk is better than exclusive breastfeeding [16]. The more mothers were exposed to information, the better their knowledge about exclusive breastfeeding [24]. For working mothers, they got more exposure to information about exclusive breastfeeding and it was obtained from magazines than other media [44, 45].

It is in line with the research of [12] in its article, it found that the failure of exclusive breastfeeding was also influenced by information because the new information 
was always sorted, whether it was in accordance with the culture and religion that existed in the community. This also affects the lifestyle of following other people and modern culture for young people nowadays who always consider themselves old when breastfeeding their babies for fear of getting sick or getting stuck in their breasts. [12].

\section{Conclusion}

The most dominant factor in the failure of exclusive breastfeeding was family support such as husbands and parents who still followed their culture, namely providing food to babies other than breast milk, the support of health workers such as some passive health workers conveyed information about exclusive breastfeeding and some of them also offered formula milk, and the last was the mother's employment status. Working mothers faced obstacles in giving exclusive breastfeeding to their babies, due to time allocation with babies, no time to express breast milk, workload stress and mother's trust to give exclusive breastfeeding.

It is expected that there will be further research with better methods to produce reliable scientific evidence to be used as references and information about the factors that hinder the success of exclusive breastfeeding. In addition, next researcher is expected to be able to conduct reviews on the same topic, but it focuses more on examining research articles in Indonesia.

\section{Acknowledgement}

The researcher would like to thank Dr. Dra. R Sitti Nur Djanah., SKM., M. Kes, Dr. dr. Prima Dhewi R., M. Biotech, Dwi Ernawati, SST., M. Keb for their advice and support in completing this review.

\section{Conflict of Interest Statement}

The authors declare there is no conflicts of interests.

\section{About the Authors}

Yuliandary Yunus is a student at magister Program in Midwifery, Faculty of Health Science, Aisyiyah University Yogyakarta. Research Interests: exclusive breastfeeding, maternal and child health.

Dr. Prima Dhewi Ratrikaningtyas, M.Biotech, is a lecturer at the Master of Community Health Science, Faculty of Medical, Public Health, and Nursing, Gadjah Mada University. Research interests: reproductive health, women's health, population health, public health.

Dwi Ernawaty, M. Keb, is a Lecturer in the magister Program in Midwifery, Faculty of Health Science, Aisyiyah University Yogyakarta. Research interests: exclusive breastfeeding, public health. 


\section{References}

[1] L. Salmon, "Food security for infants and young children: An opportunity for breastfeeding policy?," Int. Breastfeed. J., vol. 10, no. 1, pp. 1-13, 2015, doi: 10.1186/s13006015-0029-6.

[2] L. J. Brown and R. Sear, "Are mothers less likely to breastfeed in harsh environments? Physical environmental quality and breastfeeding in the Born in Bradford study," Matern. Child Nutr., vol. 15, no. 4, 2019, doi: 10.1111/mcn.12851.

[3] E. Santacruz-Salas, I. Aranda-Reneo, A. Segura-Fragoso, A. I. Cobo-Cuenca, J. A. Laredo-Aguilera, and J. M. Carmona-Torres, "Mothers' expectations and factors influencing exclusive breastfeeding during the first 6 months," Int. J. Environ. Res. Public Health, vol. 17, no. 1, pp. 3-5, 2020, doi: 10.3390/ijerph17010077.

[4] H. Arksey and L. O'Malley, "Scoping studies: Towards a methodological framework," Int. J. Soc. Res. Methodol. Theory Pract., vol. 8, no. 1, pp. 19-32, 2005, doi: 10.1080/1364557032000119616.

[5] K. Jamie, L. McGeagh, H. Bows, and R. O'Neill, “'I just don't think it's that natural': adolescent mothers' constructions of breastfeeding as deviant," Sociol. Heal. Illn., vol. 42, no. 7, pp. 1689-1708, 2020, doi: 10.1111/1467-9566.13157.

[6] P. J. Perera, N. Ranathunga, M. P. Fernando, W. Sampath, and G. B. Samaranayake, "Actual exclusive breastfeeding rates and determinants among a cohort of children living in Gampaha district Sri Lanka: A prospective observational study," Int. Breastfeed. J., vol. 7, pp. 1-6, 2012, doi: 10.1186/1746-4358-7-21.

[7] M. L. Gianni et al., "Breastfeeding difficulties and risk for early breastfeeding cessation," Nutrients, vol. 11, no. 10, pp. 1-10, 2019, doi: 10.3390/nu11102266.

[8] A. Keely, J. Lawton, V. Swanson, and F. C. Denison, "Barriers to breast-feeding in obese women: A qualitative exploration," Midwifery, vol. 31, no. 5, pp. 532-539, 2015, doi: 10.1016/j.midw.2015.02.001.

[9] F. Göksen, "Normative vs. attitudinal considerations in breastfeeding behavior: Multifaceted social influences in a developing country context," Soc. Sci. Med., vol. 54, no. 12, pp. 1743-1753, 2002, doi: 10.1016/S0277-9536(01)00145-9.

[10] S. Attard Montalto, H. Borg, M. Buttigieg-Said, and E. J. Clemmer, "Incorrect advice: the most significant negative determinant on breast feeding in Malta," Midwifery, vol. 26, no. 1, pp. e6-e13, 2010, doi: 10.1016/j.midw.2008.06.002.

[11] J. Ayton, E. Hansen, S. Quinn, and M. Nelson, "Factors associated with initiation and exclusive breastfeeding at hospital discharge: Late preterm compared to 37 week gestation mother and infant cohort," Int. Breastfeed. J., vol. 7, pp. 1-6, 2012, doi: 10.1186/1746-4358-7-16.

[12] J. E. Ayton, L. Tesch, and E. Hansen, "Women's experiences of ceasing to breastfeed: Australian qualitative study," BMJ Open, vol. 9, no. 5, 2019, doi: 10.1136/bmjopen-2018-026234.

[13] K. Al Dasoqi, R. Safadi, E. Badran, A. S. Basha, S. Jordan, and M. Ahmad, "Initiation and continuation of breastfeeding among jordanian first-time mothers: A 
prospective cohort study," Int. J. Womens. Health, vol. 10, pp. 571-577, 2018, doi: 10.2147/IJWH.S175850.

[14] E. H. Emmott, A. E. Page, and S. Myers, "Typologies of postnatal support and breastfeeding at two months in the UK," Soc. Sci. Med., vol. 246, no. September 2019, p. 112791, 2020, doi: 10.1016/j.socscimed.2020.112791.

[15] C. Lechosa-Muñiz et al., "Factors associated with duration of breastfeeding in Spain: A cohort study," Int. Breastfeed. J., vol. 15, no. 1, pp. 1-9, 2020, doi: 10.1186/s13006020-00324-6.

[16] K. Y. W. Lok, D. L. Bai, and M. Tarrant, "Predictors of breastfeeding initiation in Hong Kong and Mainland China born mothers," BMC Pregnancy Childbirth, vol. 15, no. 1, pp. 1-11, 2015, doi: 10.1186/s12884-015-0719-5.

[17] A. Patel et al., "Rates and determinants of early initiation of breastfeeding and exclusive breast feeding at 42 days postnatal in six low and middle-income countries: A prospective cohort study," Reprod. Health, vol. 12, no. 2, pp. 1-11, 2015, doi: 10.1186/17424755-12-S2-S10.

[18] J. Stockdale, M. Sinclair, G. Kernohan, E. McCrum-Gardner, and J. Keller, "Sensitivity of the breastfeeding motivational measurement scale: A known group analysis of first time mothers," PLoS One, vol. 8, no. 12, pp. 1-7, 2013, doi: 10.1371/journal.pone.0082976.

[19] Tarrant, M., Dodgson, J. E., \& Wu, K. M. (2014). Factors contributing to early breast-feeding cessation among Chinese mothers: an exploratory study. Midwifery, 30(10), 1088-1095.

[20] L. Hunt and G. Thomson, "Pressure and judgement within a dichotomous landscape of infant feeding: a grounded theory study to explore why breastfeeding women do not access peer support provision," Matern. Child Nutr., vol. 13, no. 2, pp. 113, 2017, doi: 10.1111/mcn.12279.

[21] E. L. Tuthill, J. M. McGrath, M. Graber, R. M. Cusson, and S. L. Young, "Breastfeeding Self-efficacy: A Critical Review of Available Instruments," J. Hum. Lact., vol. 32, no. 1, pp. 35-45, 2016, doi: 10.1177/0890334415599533.

[22] R. L. Spencer, S. Greatrex-White, and D. M. Fraser, "'I thought it would keep them all quiet'. Women's experiences of breastfeeding as illusions of compliance: An interpretive phenomenological study," J. Adv. Nurs., vol. 71, no. 5, pp. 1076-1086, 2015, doi: 10.1111/jan.12592.

[23] I. Williamson, D. Leeming, S. Lyttle, and S. Johnson, "'It should be the most natural thing in the world': Exploring first-time mothers' breastfeeding difficulties in the UK using audio-diaries and interviews," Matern. Child Nutr., vol. 8, no. 4, pp. 434-447, 2012, doi: 10.1111/j.1740-8709.2011.00328.x.

[24] M. Salih, "Relactation in lactation failure and low milk supply," Sudan. J. Paediatr., vol. 18, no. 1, pp. 39-47, 2018, doi: 10.24911/sjp.2018.1.6.

[25] F. A. Ogbo, A. Page, J. Idoko, and K. E. Agho, "Population attributable risk of key modifiable risk factors associated with non-exclusive breastfeeding in Nigeria," BMC Public Health, vol. 18, no. 1, pp. 1-10, 2018, doi: 10.1186/s12889-018-5145-y. 
[26] C. Odar Stough, A. S. Khalsa, L. A. Nabors, A. L. Merianos, and J. Peugh, "Predictors of Exclusive Breastfeeding for 6 Months in a National Sample of US Children," Am. J. Heal. Promot., vol. 33, no. 1, pp. 48-56, 2019, doi: $10.1177 / 0890117118774208$.

[27] M. Behzadifar et al., "Prevalence of exclusive breastfeeding practice in the first six months of life and its determinants in Iran: A systematic review and meta-analysis," BMC Pediatr., vol. 19, no. 1, pp. 1-10, 2019, doi: 10.1186/s12887-019-1776-0.

[28] E. E. Jardine, J. McLellan, and S. U. Dombrowski, "Is being resolute better than being pragmatic when it comes to breastfeeding? Longitudinal qualitative study investigating experiences of women intending to breastfeed using the Theoretical Domains Framework," J. Public Heal. (United Kingdom), vol. 39, no. 3, pp. e88-e94, 2017, doi: 10.1093/pubmed/fdw073.

[29] O. Nkoka, P. A. M. Ntenda, V. Kanje, E. B. Milanzi, and A. Arora, "Determinants of timely initiation of breast milk and exclusive breastfeeding in Malawi: A populationbased cross-sectional study," Int. Breastfeed. J., vol. 14, no. 1, pp. 1-9, 2019, doi: 10.1186/s13006-019-0232-y.

[30] V. A. A. L. Silva, M. F. C. Caminha, S. L. Silva, V. M. S. B. D. Serva, P. T. A. C. C. Azevedo, and M. B. Filho, "Maternal breastfeeding: indicators and factors associated with exclusive breastfeeding in a subnormal urban cluster assisted by the Family Health Strategy," J. Pediatr. (Rio. J)., vol. 95, no. 3, pp. 298-305, 2019, doi: 10.1016/j.jped.2018.01.004.

[31] C. N. Ihudiebube-Splendor et al., "Exclusive Breastfeeding Knowledge, Intention to Practice and Predictors among Primiparous Women in Enugu South-East, Nigeria," J. Pregnancy, vol. 2019, 2019, doi: 10.1155/2019/9832075.

[32] S. J. Charlick, A. Fielder, J. Pincombe, and L. McKellar, "'Determined to breastfeed': A case study of exclusive breastfeeding using interpretative phenomenological analysis," Women and Birth, vol. 30, no. 4, pp. 325-331, 2017, doi: 10.1016/j.wombi.2017.01.002.

[33] P. Robiquet et al., "Observation of skin-to-skin contact and analysis of factors linked to failure to breastfeed within 2 hours after birth," Breastfeed. Med., vol. 11, no. 3, pp. 126-132, 2016, doi: 10.1089/bfm.2015.0160.

[34] Z. Zhang, Y. Zhu, L. Zhang, and H. Wan, "What factors influence exclusive breastfeeding based on the theory of planned behaviour," Midwifery, vol. 62, pp. 177-182, 2018, doi: 10.1016/j.midw.2018.04.006.

[35] S. Buttham, K. Kongwattanakul, N. Jaturat, and S. Soontrapa, "Rate and factors affecting non-exclusive breastfeeding among Thai women under the breastfeeding promotion program," Int. J. Womens. Health, vol. 9, pp. 689-694, 2017, doi: 10.2147/IJWH.S148464.

[36] K. Y. W. Lok, D. L. Bai, and M. Tarrant, "Family members' infant feeding preferences, maternal breastfeeding exposures and exclusive breastfeeding intentions," Midwifery, vol. 53, pp. 49-54, 2017, doi: 10.1016/j.midw.2017.07.003.

[37] T. Tewabe, A. Mandesh, T. Gualu, G. Alem, G. Mekuria, and H. Zeleke, “Exclusive breastfeeding practice and associated factors among mothers in Motta town, East Gojjam 
zone, Amhara Regional State, Ethiopia, 2015: A cross-sectional study," Int. Breastfeed. J., vol. 12, no. 1, pp. 1-7, 2017, doi: 10.1186/s13006-017-0103-3.

[38] S. Finnie, R. Peréz-Escamilla, and G. Buccini, "Determinants of early breastfeeding initiation and exclusive breastfeeding in Colombia," Public Health Nutr., 2019, doi: 10.1017/S1368980019002180.

[39] L. Mattar, M. Hobeika, R. K. Zeidan, P. Salameh, and C. Issa, "Determinants of Exclusive and Mixed Breastfeeding Durations and Risk of Recurrent Illnesses in Toddlers Attending Day Care Programs Across Lebanon," J. Pediatr. Nurs., vol. 45, pp. e24-e34, 2019, doi: 10.1016/j.pedn.2018.12.015.

[40] K. A. Susiloretni, H. Hadi, M. M. Blakstad, E. R. Smith, and A. H. Shankar, “Does exclusive breastfeeding relate to the longer duration of breastfeeding? A prospective cohort study," Midwifery, vol. 69, pp. 163-171, 2019, doi: 10.1016/j.midw.2018.11.008.

[41] Q. N. T. Le et al., "Factors associated with a low prevalence of exclusive breastfeeding during hospital stay in urban and semi-rural areas of southern Vietnam," Int. Breastfeed. J., vol. 13, no. 1, pp. 1-10, 2018, doi: 10.1186/s13006-018-0188-3.

[42] R. S. Farr, F. Rahman, M. A. O'Riordan, and L. Furman, "Assessing the Feasibility and Effectiveness of Two Prenatal Breastfeeding Intervention Apps in Promoting Postpartum In-Hospital Exclusive Breastfeeding.," Breastfeed. Med., vol. XX, no. Xx, pp. 1-7, 2019, doi: 10.1089/bfm.2019.0053.

[43] B. Adugna, H. Tadele, F. Reta, and Y. Berhan, "Determinants of exclusive breastfeeding in infants less than six months of age in Hawassa, an urban setting, Ethiopia," Int. Breastfeed. J., vol. 12, no. 1, pp. 4-11, 2017, doi: 10.1186/s13006-017-0137-6.

[44] M. L. Giannì et al., "Exploring the Emotional Breastfeeding Experience of FirstTime Mothers: Implications for Healthcare Support," Front. Pediatr., vol. 8, no. May, pp. 1-7, 2020, doi: 10.3389/fped.2020.00199.

[45] Wihardjo, R. S. D., Nurani, Y., \& Ramadhan, S. (2020). The Comparison between the Effectiveness of Guided Discovery Model and Inquiry Model for Early Childhood Education Students. International Journal of Innovation, Creativity and Change, 11(3), 409-418. 
Creative Commons licensing terms

Author(s) will retain the copyright of their published articles agreeing that a Creative Commons Attribution 4.0 International License (CC BY 4.0) terms will be applied to their work. Under the terms of this license, no permission is required from the author(s) or publisher for members of the community to copy, distribute, transmit or adapt the article content, providing a proper, prominent and unambiguous attribution to the authors in a manner that makes clear that the materials are being reused under permission of a Creative Commons License. Views, opinions and conclusions expressed in this research article are views, opinions and conclusions of the author(s). Open Access Publishing Group and European Journal of Public Health Studies shall not be responsible or answerable for any loss, damage or liability caused in relation to/arising out of conflicts of interest, copyright violations and inappropriate or inaccurate use of any kind content related or integrated into the research work. All the published works are meeting the Open Access Publishing requirements and can be freely accessed, shared, modified, distributed and used in educational, commercial and non-commercial purposes under a Creative Commons Attribution 4.0 International License (CC BY 4.0). 